Proceedings

\title{
Testimony: A Matter of Social Practices ${ }^{\dagger}$
}

\section{Raffaela Giovagnoli}

Faculty of Philosophy, Pontifical Lateran University, 00184 Roma, Italy; giovagnoli@pul.it

+ The Fourth International Conference on Philosophy of Information, Berkeley, California, USA, 2-6 June 2019.

Published: 13 May 2020

\begin{abstract}
Traditional epistemology rests on sources of information and knowledge such as perception, memory, ways of reasoning etc. In social epistemology, we find the primacy of an "indirect" form of information and knowledge, namely "testimony": a justified belief can be acquired by hearing what others say or write. We focus on the contemporary debate, and in particular, on "communitarian" views.
\end{abstract}

Keywords: testimony; reductionism; anti-reductionism; communitarian epistemology

\section{Introduction}

The ongoing debate on "testimony" is very lively and presents interesting, contrasting perspectives [1]. A classical distinction concerns "direct" or "indirect" forms of information and knowledge. Hume maintained that testimony is an indirect source of knowledge, as even though we generally trust what others say, we are authorized to trust them by virtue of what we have learned by using direct forms of knowledge.

This type of testimony is called "reductionism", as it reduces the force of justification to the combined forces of perception, memory and inductive inference. More precisely, this form of justification is called "global reductionism", because it allows the auditors to be justified to believe a peculiar example of testimony through inferential reference to the general reliability of testimony.

An alternative to global reductionism is "local reductionism", which does not require an auditor to be justified to believe that testimony is reliable. It only requires that the speaker responsible for the testimony would be reliable and sincere about the dealt topic. We can observe that this is a weaker and simpler requisite to be satisfied in comparison with global reductionism.

Another view about testimony is "anti-reductionism" (Coady, Burge, Foley). According to antireductionism, we can introduce a weaker condition, namely that the hearer would not have evidence that could affect the testimony. As we have seen, because this requirement is too weak, some authors think that we need to test the reliability and sincerity of the speaker.

A third, interesting view about testimony is the "interpersonal" approach, which rejects the requirements introduced by reductionism and anti-reductionism (Ross, Hinchman, Moran, Faulkner, Zagzebski). In this case, testimony is valid by virtue of the fact that it is a "warranty" by its nature. In this case, justification via testimony derives from the fact that the speaker assumes responsibility for the truth of her assertion (Moran) or invites the hearer to trust her (Hinchman).

\section{Communitarian Epistemology}

Starting from Hardwig's work [2], Martin Kusch isolates three epistemological alternatives [3]:

1. "Strong individualism" according to which knowledge presupposes individual sources of evidence. 
2. "Weak individualism" according to which it is not necessary to possess evidence for the truth of what one believes and to completely understand what one knows.

3. "Communitarianism" according to which community is the primary source of knowledge. It retains the idea that an agent would have "direct" possession of the evidence, but it breaks with the assumption that such agent would or could be an individual.

Hardwig could be considered as a communitarian not only regarding epistemology but also philosophy in general. Testimony occupies a space where epistemology meets ethics. If a certain result by an expert provides good reason to believe that, it will depend on the perception of the receiver about the reliability of the testimony of the expert, that for its part will depend on an evaluation of her character. Hardwig's work on teams and trust in scientific practice has influenced relevant authors in the field of social epistemology (Galison, Knorr Cetina, Shaffer, Shapin and Mackenzie). Kusch underscores two limitations of his approach. First, Hardwig privileges scientific communities, so he does not consider cases of cooperation in ordinary life where testimony plays a crucial role. Indeed, we trust a lot of public messages without investigating the sincerity and the competence of the source. Second, the way in which Hardwig refers to the evidence of a true belief is not very clear. Beyond individualism, there is an explanation either of the nature of the evidence possessed by the teams or of the process through which we can proceed to a true belief.

Michael Welbourne wrote the book The Community of Knowledge, which represents a valid example of communitarian epistemology based on testimony [4]. He makes a fundamental theoretical move; he considers testimony not as "mere transmission of information" (the so called "say so" which characterizes classical epistemology). Knowledge takes place in a community where it is transmitted according to a certain view of "shared knowledge". To share knowledge means to share commitments and entitlements with others. His theory of "authority" conflicts with the theory of evidence. We do not have direct evidence for knowledge, because with entitlement, simply anything can serve as ground for our inferences. Knowledge must be objective and so "social" because we consider it as an external and objective standard for what also others should recognize. Commitments we undertake entail an investigation on the entitlements of the others; therefore, we create a dialogical dynamic that generates new shared knowledge. The greatest limit of Welbourne's view is, according to Kusch, that he does not consider the normative ground of testimony, namely background knowledge. This background represents what agents concretely share and encloses the important results of previous communities of knowledge from which we inherit them.

Therefore, it would be possible to go beyond the dialogical exchange of reasons, starting from commitments and entitlements and to proceed on knowledge constituted by testimony through a sort of "institutionalization". In this case, we need a theory of social institutions and social states based on the use of the so-called "performatives" (Austin). The major referents for social epistemology in this context are John Searle, Barry Barnes and David Bloor. However, we recall also the work of Kent Bach, Esalkonen, Eerik Lagerspetz and Raimo Tuomela. Performative testimony moves from the act we perform by saying anything and from how it is received by our interlocutor. It is not a matter of the simple "say so" or mere transmission, but a process of social construction.

\section{A Social Notion of the "Space of Reasons"}

According to Kush, knowledge is a matter of consensus and this theoretical option characterizes his communitarianism. Differently, Robert Brandom does not refer to knowledge by agreement and Kusch criticized his perspective because he thinks that a "We-perspective" is prior to an "I-Thou perspective". Yet, according to Brandom, it exists a structure of the concepts we learn to use by learning language $[5,6]$. Following Sellars, we can refer to the metaphor of the "space of reasons", but he understands it as a "social concept", i.e., as the space of the intersubjective justification of our assertions. Assertions possess a content that is inferentially structured. This option entails material inferential commitments we come to know in the process of language acquisition. Discursive practices are characterized by the inferential articulation of normative senses embedded in assertions and, therefore, by the attribution of conceptual content to states, attitudes, actions and expressions. When we assert something, we undertake a certain kind of commitment. The structure of this 
commitment emerges in social practices where the participants keep score by taking adequate deontic attitudes: they attribute commitments and corresponding entitlements and recognize them themselves. Moreover, from the point of view of social epistemology, beliefs, mental states, attitudes and actions possess a content because of the role they play in social "normative practices" $([7,8]$ Giovagnoli). This content must be recognized by the agents in communication and action. Therefore, together with the semantics of concept use, we need pragmatics implicit in the attitudes we undertake in communication. Generally speaking, what we normally do is undertake commitments that others must recognize and attribute as we are entitled to them. We also attribute commitments and entitlements to others (this dialogical model of testimony includes not only assertions but also challenges, denials and questions). Rather than relativism, we are here concerned with a form of perspectivism, as concepts develop and change according to the work required in the ongoing research.

Our assertions have a "sense" or are "contentful" by virtue of three dimensions of inferential social practices. To the first dimension belongs the commitment-preserving inference that corresponds to the material deductive inference. For example, if $A$ is to the west of $B$, then $B$ is to the east of $\mathrm{A}$, and the entitlement preserving inference that corresponds to inductive inference, such as if a thermometer is well made then it will indicate the right temperature. This dimension is structured also by incompatibility relations: two claims have materially incompatible contents if the commitment to the one precludes the entitlement to the other. The second dimension concerns the distinction between the concomitant and the communicative inheritance of deontic statuses. To the concomitant inheritance corresponds the intrapersonal use of a claim as a premise. In this case, if a person is committed to a claim is, at the same time, committed to other concomitant claims as consequences. Correspondently, a person entitled to a commitment can be entitled to others by virtue of permissive inferential relations. Moreover, incompatibility relations imply that to undertake a commitment has, as its consequence, the loss of the entitlement to concomitant commitments to which one was before entitled. To the communicative inheritance corresponds the interpersonal use of a claim, because to undertake a commitment has, as its "social" consequence, to entitle others to the "attribution" of that commitment. The third dimension shows the two aspects of the assertion as "endorsed": the first aspect is the "authority" to other assertions and the second aspect dependent to the first is the "responsibility" through which an assertion becomes a "reason" enabling the inheritance of entitlements in social contexts. The entitlement to a claim can be justified (1) by giving reasons for it, or (2) by referring to the authority of another agent, or (3) by demonstrating the capacity of the agent reliably to respond to environmental stimuli. The scorekeeping model is based on a notion of entitlement that presents a structure of "default" and "challenge". This model is fundamental in order to ground a pragmatic and social model of justification, which requires the participation to the game of giving and asking for reasons. A fundamental consequence of this description is that the deontic attitudes of the interlocutors represent a perspective on the deontic states of the entire community.

Funding: This research received no external funding.

Acknowledgments: I would like to thank the organizers of this very interesting conference for the publication of my contribution, I also thank the organizers of IS4SI 2019 and Lorenzo Magnani, Gordana Dodig-Crnkovic and Gianfranco Basti for their helpful reading of my work.

Conflicts of Interest: The author declares no conflict of interest.

\section{References}

1. Goldman, A. Social Epistemology, Stanford Encyclopedia of Philosophy. 2015. Available online: https://plato.stanford.edu/entries/epistemology-social/ (accessed on 28 August 2019).

2. Hardwig, J. The Role of Trust to Knowledge. J. Philos. 1991, 88, 693-708.

3. Kusch, M. Knowledge by Agreement; Oxford University Press: Oxford, UK, 2002.

4. Welbourne, M. The Community of Knowledge; Gregg Revivals: Aldershot, UK, 1993.

5. Brandom, R. Making It Explicit; Cambridge University Press: Cambridge, UK, 1994. 
6. Brandom, R. Between Saying and Doing; Oxford University Press: Oxford, UK, 2008.

7. Giovagnoli, R. "Indirect Information": The Debate on Testimony in Social Epistemology and Its Role in the Game of Giving and Asking for Reasons. Information 2019, 10, 101. Available online: https://www.mdpi.com/2078-2489/10/3/101 (accessed on 7 March 2019).

8. Giovagnoli, R. A Pragmatic Model of Justification Based on “Material Inference” for Social Epistemology. In Model-based Reasoning in Science and Technology. Inferential Models for Logic, Language, Cognition and Technology; Nepomuceno, F., Magnani, L., Selguero-Lamiller, L., Barez-Gomez, F.J., Eds.; Springer: Cham, Switzerland, 2019; pp. 55-68.

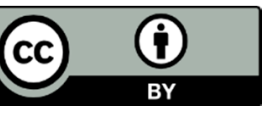

(C) 2020 by the authors. Licensee MDPI, Basel, Switzerland. This article is an open access article distributed under the terms and conditions of the Creative Commons Attribution (CC BY) license (http://creativecommons.org/licenses/by/4.0/). 